\title{
Comparing Emotional Creativity and Social Adjustment of Gifted and Normal Students
}

\author{
Hossien Jenaabadi1 ${ }^{*}$, Afsaneh Marziyeh1, Abdulwahab Mohammadi Dadkan² \\ ${ }^{1}$ Department of Education, Faculty of Educational Sciences and Psychology, University of Sistan and \\ Baluchestan, Zahedan, Iran \\ ${ }^{2}$ Faculty of Educational Sciences and Psychology, University of Sistan and Baluchestan, Zahedan, Iran \\ Email: " hjenaabadi@ped.usb.ac.ir
}

Received 3 December 2014; accepted 13 January 2015; published 16 March 2015

Copyright (C) 2015 by authors and Scientific Research Publishing Inc.

This work is licensed under the Creative Commons Attribution International License (CC BY). http://creativecommons.org/licenses/by/4.0/

(c) (i) Open Access

\begin{abstract}
The present study aimed to compare emotional creativity and social adjustment of gifted and normal high school freshman students (first period) in Khash. This is a casual-comparative study. To this end, a total of 200 students, among which gifted students were selected using census method and normal students were selected applying multistage random sampling methods, were chosen. The subjects were evaluated using Averill's Emotional Creativity Inventory (2013) and Sinha and Singh's Social Adjustment Inventory (1993). To describe the obtained data, frequency table, mean and standard deviation were applied and for analyzing the data, independent $t$-test and one-way analysis of variance were used. The results indicated that there was a significant difference between gifted and normal students and also between male and female gifted students and normal students considering emotional creativity and its components. However, no significant difference was found with regard to social adjustment. The means of emotional creativity and components of novelty, effectiveness and authenticity of gifted students were higher than those of normal students. Moreover, the means of emotional creativity and components of novelty and preparedness of female gifted students and the means of components of effectiveness and authenticity of male gifted students were higher than other groups.
\end{abstract}

\section{Keywords}

Emotional Creativity, Social Adjustment, Gifted Students, Normal Students

\footnotetext{
${ }^{*}$ Corresponding author.
} 


\section{Introduction}

Gifted children and adolescents benefit from high levels of mental capacity, creativity, artistic talent and leadership ability or they are considerably superior in a specific academic field compared to their counterparts (HosseinKhanzadeh, 2013: 113-116). Being curious and thinking about excelled and talented people have a long history dating back to two thousand years ago. It possibly goes back to when human was initially interested in perceiving why people are different. In fact, great abilities and rich effectiveness of gifted people aid us to find appropriate solutions for humanitarian issues globally and lead to broad and comprehensive progress in science, technology, art, culture and literature (AkbariCharmahini, 1999).

Emotional creativity is a structure associated with emotion. Using emotional creativity, one can define emotions as concepts of objective and subjective creative efforts. Based on his social constructionist perspective, Averill (2013) defined four main criteria of creativity. His description of these four dimensions of creativity (novelty, effectiveness, authenticity and preparedness) is as follows:

Novelty: Novelty means a new response compared to individual's previous behavior or in general, compared to normal behaviors in a society. Moreover, it should also be relevant to our present purposes. It should also be noted that creativity is not a unique feature limited to only a small number of individuals. Acquisition of a new behavior is essential for human development; hence, some levels of creativity are necessary for each individual.

Effectiveness: Not all responses are creative. Some of them seem strange and unusual. For being creative, a response should be potentially helpful for a person or a group.

Authenticity: A creative answer is reflected in some styles of an individual values and beliefs about the world. This is considered as a tool itself.

Preparedness: The dimension of preparedness that is mentioned by Averill is similar to Wallace's creative stage which has stressed in the creative process. Undoubtedly, years of preparation is required to achieve the actual creativity in a particular field (Ebrahimi, 2006). Individual differences in emotional creativity ability should be evaluated using the application of three criteria of creativity, i.e., effectiveness, modernization and trust in an individual's previous behavior. Assuming that past predicts future, preparedness is another potential indicator of individual differences regarding their potential for creativity before a person is really capable of performing something creative in a particular field. Having skill, knowledge and scientific understanding in that particular field are of great importance (Ghadirinejad, 2002).

Man is a social being always, from his birth until the last moment of his life, interacting and cooperating with other human beings inevitably in order to live and preserve his welfare, since his various needs force him to use others' help and assistance to solve his problems, remove obstacles and move day by day toward perfection. Social adjustment is a person's compatibility with his/her social environment which may be obtained as the result of changing himself/herself or altering the environment. In addition, social adjustment can be considered as a reflection of a person's interaction with others, satisfaction with his/her role and his/her performance in that role which is likely under the influence of previous character, culture and family expectations (AlamMehrjerdi, 2003).

Some scholars consider social adjustment equivalent with social skills. In this regard, Elliut and Gresham (2009) defined social adjustment as learned adaptive behaviors that enable people to interact with others, express positive responses and also avoid inappropriate behaviors. They divided required skills into five categories: cooperation, appropriate speech, responsibility, empathy and continence (JavanSheikhi, 2001). Social adjustment is a standard measure of social development. Other words, a person's social developmentis measured regarding his/her social adjustment with others. This “others” includes everyone, from friends, teachers and family members to neighbors and even those who are dealt with for the first time (Razavian, 2005).

One of the most important and fundamental issues of education in the present era is considering the methods of educating students in a way that their emotional creativity and social adjustment be proportionate and coordinated with today's complex and highly variable conditions and also future challenging situations. Emotional creativity requires divergent thinking process and creation of appropriate, and yet authentic, responses (Averill, 2007, as cited in Hashemi, 2009). Social adjustment in adolescents, as the main symptom of mental health, is one of the topics of interest and is really significant (Atkinson and Hilgard, 2004, as cited in Yarmohammadian \& Sharafrad, 2011).

Suragy (1996) concluded that there was a significant difference between mean scores of creativity of gifted female and male students. In other words, male students were more creative compared to female students. Pasha 
Sharifi and Ghodrati (2010) indicated that considering creativity, there was a significant difference between female gifted students studying in schools for exceptional talents, public schools and private schools. Sabri, Alborzi and Bahrami (2013) demonstrated that there was no significant difference between male and female students' emotional intelligence and emotional creativity.

Kousari (2001) concluded that there was a significant difference between male and female students considering their total, individual and social adjustment. Other words, female students, compared to male students, had more total, individual and social adjustment.

Behpazhouh (2008) asserted that regarding mental health and social adjustment, there was no significant difference among gifted students in three educational settings. These results indicated that female gifted students, studying in schools for exceptional talents, special private schools and public schools, had high levels of mental health and social adjustment.

Therefore, it is essential to consider variables of emotional creativity and social adjustment with respect to individual differences. Attempting to achieve the data obtained in this way has a significant impact on manner and extent of services provided for gifted students and also making decisions for these students. Given the importance of the issue and considering the fact there are few previously conducted studies carried out on this issue, the present study aims to find the differences of emotional creativity and social adjustment between high school freshman male and female gifted students and normal students (first period) in Khash.

\section{Methods}

This is a casual-comparative study. The study population included all seven-grade high school students (first term) studying in public schools, schools for exceptional talents, non-profit and private schools and schools with board of trustee in Khash in the academic year 2014-2015. According to the statistics gained from department of education in Khash, there were 1339 students among which 49 individuals were male gifted student, 51 individuals were female gifted students, 695 individuals were normal male students and 544 individuals were normal female students. Since there was only a school for exceptional talents for male students and female students and in each school, there were only two seven-grade classes, therefore, the total number of 100 seven-grade students (49 males and 51 females) were selected and placed in the first group. Moreover, for selecting normal students, multistage random sampling method was applied in a way that a school for males and a school for females were randomly selected. In each school, 4 classes were randomly selected and from each class, 12 students were randomly chosen. Additionally, to have equal number of normal and gifted students, from a class in a school for females and a school for males, 15 and 13 students were selected respectively. A total of 100 seventh graders (49 males and 51 females) were placed in this group. The sample size was 200 students. To investigate the differences between male and female gifted students and normal students considering their emotional creativity and social adjustment, two following questionnaires were used.

1) Emotional Creativity Inventory (1999): This is a pen and paper self-report scale. This tool measures four components of emotional creativity, i.e. novelty, effectiveness, authenticity and preparedness, and it has content validity. Reliability coefficients of emotional creativity, subscales of authenticity, effectiveness, novelty and preparedness were $0.89,0.81,0.75$ and 0.63 , respectively.

\begin{tabular}{cc}
\hline Subscales of Emotional Creativity & Question Numbers \\
\hline Novelty & $1-6-8-10-14-16-18-19-21-23-24-26-28-30$ \\
Preparedness & $2-5-7-11-15-20-27$ \\
Authenticity/Effectiveness, & $3-4-9-12-13-17-22-25-29$ \\
\hline
\end{tabular}

2) Sinha and Singh's Social Adjustment Inventory (1993): This questionnaire was developed in India by Sinha A. K. in the Shankar University and Singh A. K. in the Panetta University, to determine students' social adjustment. It includes 20 two alternative options questions (yes or no). For scoring, responses, in accordance with adjustment, get 1 and those which are not in line with adjustment get 0 . This inventory has content validity. Reliability coefficient of social adjustment, using Cronbach's alpha coefficient and Kuder-Richardson coefficient, was 0.60 and 0.95 , respectively. 


\section{Data Analysis}

Analyzing the data was conducted in two levels of descriptive and inferential statistics. In the descriptive level, to describe subjects' status considering variables under study, mean and standard deviation and in the inferential level, for testing research hypotheses and variables under study, independent t-test and one-way ANOVA were used. It is worth noting that to analyze the obtained data, SPSS software version 21 was applied.

\section{Results}

\section{Inferential Analysis (Investigating Research Questions)}

First Research Question: Is there any significant difference between first grade gifted and normal high school students (first term) considering emotional creativity and its components?

Results demonstrated in Table 1 indicate that there is no significant difference between gifted and normal students considering preparedness $(p<0.05)$. However, there are significant differences between gifted and normal students with regard to components of novelty, effectiveness, authenticity and emotional creativity, at 99\% confidence level $(p<0.01)$, i.e. according to Table 1 , gifted students have higher mean scores in novelty (45.77), effectiveness and authenticity (30.38), and emotional creativity (100.26), compared to normal students.

Second Research Question: Is there any significant difference between first grade male and female giftedand normal high school students (first period) considering emotional creativity and its components?

Results represented in Table 2 suggest that according to calculated F with degrees of freedom 3 and 196, there is a significant difference between male and female gifted students and normal students considering emotional creativity (6.987) and components of novelty (6.409), effectiveness and authenticity (5.576) at 99\% confidence level. This means that the level of emotional creativity and components of novelty, effectiveness and authenticity are not the same among male and female gifted students and normal students $(p<0.01)$. Moreover, considering preparedness, given the calculated F (3.038) with degrees of freedom 3 and 196, there is a significant difference, i.e. the level of preparedness is not the same among male and female gifted students and normal students $(p<0.05)$.

Results of Table 3 indicate that considering the component of novelty, there are significant differences between female gifted students and normal male students, with a mean difference of 6.57 , and female gifted students and normal female students, with a mean difference of 5.19, at 95\% confidence level $(p<0.05)$. Therefore, it can be concluded that female gifted students have a higher level of novelty compared to other groups.

Regarding preparedness, the results indicate that there is a significant difference between female gifted students and normal female students, with a mean difference of 2.34 , at the $95 \%$ confidence level $(p<0.05)$. Therefore, it can be concluded that female gifted students have a higher level of preparedness compared to other groups.

With regard to effectiveness and authenticity, there are significant differences between male gifted students and normal male students, with a mean difference of 2.24, and female gifted students and normal female students, with a mean difference of 3.31, at $95 \%$ confidence level $(p<0.05)$. Therefore, it can be concluded that

Table 1. Results of independent t-test regarding comparison of emotional creativity and its components in gifted and normal students.

\begin{tabular}{|c|c|c|c|c|c|c|c|}
\hline Variable & Groups & $\mathrm{N}$ & Mean & SD & $\mathrm{t}$ & df & Sig \\
\hline \multirow{2}{*}{ Novelty } & Gifted & 100 & 45.77 & 8.18 & \multirow{2}{*}{3.737} & \multirow{2}{*}{198} & \multirow{2}{*}{0.000} \\
\hline & Normal & 100 & 41.52 & 7.89 & & & \\
\hline \multirow{2}{*}{ Preparedness } & Gifted & 100 & 24.11 & 4.08 & \multirow{2}{*}{1.38} & \multirow{2}{*}{198} & \multirow{2}{*}{0.167} \\
\hline & Normal & 100 & 23.29 & 4.27 & & & \\
\hline \multirow{2}{*}{ Effectiveness/Authenticity } & Gifted & 100 & 30.38 & 5.38 & \multirow{2}{*}{3.367} & \multirow{2}{*}{198} & \multirow{2}{*}{0.001} \\
\hline & Normal & 100 & 28.78 & 5.54 & & & \\
\hline \multirow{2}{*}{ Emotional Creativity } & Gifted & 100 & 100.26 & 13.76 & \multirow{2}{*}{3.88} & \multirow{2}{*}{1.98} & \multirow{2}{*}{0.000} \\
\hline & Normal & 100 & 92.59 & 14.19 & & & \\
\hline
\end{tabular}


Table 2. Results of one-way ANOVA regarding comparison of emotional creativity and its components in male and female gifted and normal students.

\begin{tabular}{|c|c|c|c|c|c|c|c|c|c|c|}
\hline Variables & Groups & $\mathrm{N}$ & Mean & SD & Source & Ss & df & $\mathrm{ms}$ & $\mathrm{f}$ & sig \\
\hline \multirow{5}{*}{ Novelty } & Male gifted & 49 & 44.08 & 6.99 & \multirow{2}{*}{ Intergroup } & \multirow{2}{*}{1224.58} & \multirow{2}{*}{3} & \multirow{2}{*}{408.19} & \multirow{5}{*}{6.409} & \multirow{5}{*}{0.000} \\
\hline & Female gifted & 51 & 47.39 & 8.95 & & & & & & \\
\hline & Normal male & 49 & 4082 & 7.11 & \multirow{3}{*}{ Intragroup } & \multirow{3}{*}{12483.21} & \multirow{3}{*}{196} & \multirow{3}{*}{63.69} & & \\
\hline & & & & & & & & & & \\
\hline & Normal female & 51 & 42.20 & 8.61 & & & & & & \\
\hline \multirow{4}{*}{ Preparedness } & Male gifted & 49 & 23.53 & 3.78 & \multirow{2}{*}{ Intergroup } & \multirow{2}{*}{155.06} & \multirow{2}{*}{3} & \multirow{2}{*}{51.69} & \multirow{4}{*}{3.038} & \multirow{4}{*}{0.03} \\
\hline & Female gifted & 51 & 24.67 & 4.33 & & & & & & \\
\hline & Normal male & 49 & 22.33 & 3.99 & \multirow{2}{*}{ Intragroup } & \multirow{2}{*}{3334.94} & \multirow{2}{*}{196} & \multirow{2}{*}{17.02} & & \\
\hline & Normal female & 51 & 24.22 & 4.35 & & & & & & \\
\hline \multirow{4}{*}{$\begin{array}{l}\text { Effectiveness/ } \\
\text { Authenticity }\end{array}$} & Male gifted & 49 & 30.86 & 4.62 & \multirow{2}{*}{ Intergroup } & \multirow{2}{*}{490.89} & \multirow{2}{*}{3} & \multirow{2}{*}{163.63} & \multirow{4}{*}{5.576} & \multirow{4}{*}{0.001} \\
\hline & Female gifted & 51 & 29.92 & 6.03 & & & & & & \\
\hline & Normal male & 49 & 26.61 & 5.28 & \multirow[b]{2}{*}{ Intragroup } & \multirow[b]{2}{*}{5751.83} & \multirow[b]{2}{*}{196} & \multirow[b]{2}{*}{29.35} & & \\
\hline & Normal female & 51 & 28.90 & 5.61 & & & & & & \\
\hline \multirow{4}{*}{$\begin{array}{l}\text { Emotional } \\
\text { creativity }\end{array}$} & Male gifted & 49 & 98.47 & 11.63 & \multirow{2}{*}{ Intergroup } & & & & & \\
\hline & Female gifted & 51 & 101.98 & 15.46 & & & 5 & & & \\
\hline & Normal male & 49 & 89.76 & 12.73 & & & & & & \\
\hline & Normal female & 51 & 95.31 & 15.08 & Intragroup & 37603.23 & 196 & 191.85 & & \\
\hline
\end{tabular}

Table 3. Results of Tukey's test regarding male and female gifted and normal students' emotional creativity and its components.

\begin{tabular}{|c|c|c|c|c|c|}
\hline \multirow{2}{*}{ Variable } & \multirow{2}{*}{ Groups } & \multicolumn{4}{|c|}{ Mean difference } \\
\hline & & Male gifted & Female gifted & Normal male & Normal female \\
\hline \multirow{4}{*}{ Novelty } & Male gifted & ------ & -3.31 & 3.26 & 1.88 \\
\hline & Female gifted & ------ & ------ & ${ }^{*} 6.57$ & *5.19 \\
\hline & Normal male & ------ & ----- & ------ & -1.38 \\
\hline & Normal female & ------ & ----- & ------ & ----- \\
\hline \multirow{4}{*}{ Preparedness } & Male gifted & ------ & -1.14 & 1.20 & -0.68 \\
\hline & Female gifted & ------ & ------ & ${ }^{*} 2.34$ & 0.54 \\
\hline & Normal male & ------ & ------ & ------ & -1.88 \\
\hline & Normal female & ------ & ----- & ----- & ------ \\
\hline \multirow{4}{*}{ Effectiveness/Authenticity } & Male gifted & ------ & 0.94 & ${ }^{*} 4.24$ & 1.95 \\
\hline & Female gifted & ----- & ----- & ${ }^{*} 3.31$ & 1.02 \\
\hline & Normal male & ------ & ------ & ------ & -2.29 \\
\hline & Normal female & ------ & ----- & ----- & ------ \\
\hline \multirow{4}{*}{ Emotional creativity } & Male gifted & ----- & -3.51 & ${ }^{*} 8.71$ & 3.15 \\
\hline & Female gifted & ------ & ------ & *12.22 & 6.66 \\
\hline & Normal male & ----- & ----- & ----- & -5.56 \\
\hline & Normal female & ------ & ------ & ------ & ------ \\
\hline
\end{tabular}


male gifted students have a higher level of effectiveness and authenticity compared to other groups.

Regarding emotional creativity, the results indicate that there are significant differences between male gifted students and normal male students, with a mean difference of 8.71, and female gifted students and normal male students, with a mean difference of 12.22, at 95\% confidence level $(p<0.05)$. Therefore, it can be concluded that female gifted students have a higher level of emotional creativity compared to other groups.

Third Research Question: Is there any significant difference between first grade gifted and normal high school students (first period) considering social adjustment?

These findings demonstrate that there is no significant difference between gifted students and normal students, considering social adjustment, at 95\% confidence level $(p<0.05)$.

Fourth Research Question: Is there any significant difference between high school first-grade male and female gifted students and normal high school students (first period) considering social adjustment?

Results of Table 5 indicate that with regard to social adjustment, given the calculated F, there is a significant difference between female and male gifted students and normal students, with a mean difference of 0.276 , at the $95 \%$ confidence level $(p<0.05)$. Therefore, it can be concluded that social adjustment of male and female gifted students and normal students is the same.

\section{Discussion}

The obtained results are presented based on research questions. The results in relation to the first question indicated that there was a significant difference between gifted students and normal students considering emotional creativity and components of novelty, effectiveness and authenticity, i.e. the means of emotional creativity and components of novelty, effectiveness and authenticity among gifted students, compared to normal students, were higher. This finding is in line with the results of Eisazadegan et al. (2013). Eisazadegan et al. indicated that gifted students had higher levels of novelty, effectiveness and preparedness compared to other groups. According to the results, no significant difference was found between gifted students and normal students' preparedness. This is not in line with the results of Eisazadegan et al. (2013).

Regarding the second research question, Table 4 demonstrated that there was a significant difference between male and female gifted students and normal students considering emotional creativity and components of novelty, preparedness, effectiveness and authenticity. Male gifted students had higher levels of effectiveness and authenticity and female gifted students had higher levels of emotional creativity, novelty and preparedness, compared to other groups. Since no studies have been carried out to directly examine this issue, the results of previously conducted studies related to this study are mentioned. These results are consistent with the results of Pasha Sharifi and Ghodrati (2010), Kershner and Ledger (2007), Kim and Michael (2011). In their study, PashSharifi and Ghodrati (2010) indicated that female gifted students studying in schools for exceptional talents had a higher level of creativity compared to normal female students studying in public schools. Kershner and

Table 4. Results of independent t-test regarding comparison of social adjustment of gifted and normal students.

\begin{tabular}{cccccccc}
\hline Variable & Groups & $\mathrm{N}$ & Mean & SD & $\mathrm{t}$ & Df & Sig \\
\hline $\begin{array}{c}\text { Social } \\
\text { adjustment }\end{array}$ & Gifted & 100 & 13.40 & 2.94 & & & 0.51 \\
& Normal & 100 & 13.66 & 2.63 & -0.66 & 198 & \\
\hline
\end{tabular}

Table 5. Results of one-way ANOVA regarding comparison of social adjustment of male and female gifted students and normal students.

\begin{tabular}{|c|c|c|c|c|c|c|c|c|c|c|}
\hline Variable & Groups & $\mathrm{N}$ & Mean & SD & Source & ss & df & Ms & $\mathrm{f}$ & sig \\
\hline \multirow{5}{*}{$\begin{array}{c}\text { Social } \\
\text { adjustment }\end{array}$} & Male gifted & 49 & 13.37 & 2.89 & & & & & \multirow{5}{*}{0.276} & \multirow{5}{*}{0.842} \\
\hline & Female gifted & 51 & 13.43 & 3.00 & Intergroup & 6.48 & 3 & 2.16 & & \\
\hline & Normal male & 49 & 13.84 & 2.53 & \multirow{3}{*}{ Intragroup } & \multirow{3}{*}{1533.337} & \multirow{3}{*}{196} & \multirow{3}{*}{7.82} & & \\
\hline & & & & & & & & & & \\
\hline & Normal female & 51 & 13.49 & 2.73 & & & & & & \\
\hline
\end{tabular}


Ledger (2007), in their study, demonstrated that female students' creativity was higher than that of male students. Kim and Michael (2011) showed that female students' creativity was higher than that of male students. Moreover, the obtained results are not in line with the results of Suragy (1996), Averill (2013) and Stoltzfus et al. (2011). Suragy (1996) indicated that male gifted students had a higher level of creativity compared to male gifted students. Averill (2013) demonstrated that female students' preparedness, effectiveness and authenticity were higher and their novelty was lower than those of male students. Stoltzfus et al. (2011) showed that male students' creativity was higher than that of female students.

In relation to the third research question, it was demonstrated that there was no significant difference between gifted students and normal students with regard to their social adjustment. This finding is not consistent with the results of Darkeh et al. (2011) and Lehman \& Erdwins (2014).

In relation to the fourth research question, given the results represented in Tables 1-5 using one-way ANOVA, it was indicated that there was no significant difference between male and female gifted students and normal students' social adjustment. Since no studies have been carried out to directly examine this issue, the results of previously conducted studies related to this study are mentioned. This result is in line with the results of Afsharniakan (2002), Abtahi \& Nadri (2013) and Pourakbaran (2013) demonstrating that there was no significant difference between male and female students' social adjustment. This result is not consistent with the resulta of Kousari (2001) and Behpazhouh et al. (2008). Kousari (2001) indicated that female students' social adjustment was higher than that of male students. Behpazhouh et al. (2008) demonstrated that female gifted students' social adjustment, studying in schools for exceptional talents, was higher than that of female gifted students studying in public and private schools.

\section{Our recommendations based on the obtained results are as follow:}

- Applying teaching, training and assessment methods appropriate to the level of students' thought and emotional creativity.

- Training administrators and teachers in order to identify gifted students and enhance their scientific and psychological knowledge.

- Nurturing students' emotional creativity and social adjustment.

- Enhancing parents' awareness and encouraging them as much as possible to identify their children's talents.

- Paying attention to facilities, teaching aids and methods of selecting gifted students by authorities considering international standards.

The limitation in our study can be mentioned as follow:

- The population of the current study included freshman high school students (first period) in Khash; therefore, cautious should be made in generalizing the obtained results to other regions and provinces.

- Inventories constraints.

\section{Conclusion}

The present study aimed to compare emotional creativity and social adjustment of first grade gifted and normal high school students (first period) in Khash. Being curious and thinking about excelled and talented people have a long history and scientists' growing interest in carrying out studies on gifted individuals suggests the importance of these people's role in the progress of human life. One of the most important and fundamental issues of education in the present era is considering the methods of educating students in a way that their emotional creativity and social adjustment be proportionate and coordinated with today's complex and highly variable conditions and also future challenging situations. The current study's results indicated that gifted students had higher levels of emotional creativity, novelty, effectiveness and authenticity and there was a significant difference between male and female gifted students and normal students considering emotional creativity and its components. Moreover, female gifted students' emotional creativity, novelty and preparedness were higher than those of male gifted students and male gifted students' effectiveness and authenticity were higher than those of female gifted students. Emotional creativity requires divergent thinking process and creation of appropriate, and yet authentic, responses. Investigating emotional creativity can solve a number of individual and social problems. Considering the obtained results, there was no significant difference between gifted students and normal students and also between male and female gifted students and normal students. Social adjustment is a symptom of mental health and is a criterion for measuring social development. Family factors, education, peer groups and intelligence have great impacts on social adjustment. 


\section{References}

Abtahi, M., \& Nadri, Kh. (2013). The Relationship of Creativity and Social Adjustment with Academic Performance in High School Students in Zanjan. Journal of Educational Administration, 2, 15-28.

Afsharniakan, S. (2002). Investigating and Comparing Emotional, Social and Educational Adjustment in Male and Female Students in the Fields of Mathematics, Experimental Science and Humanities. MA Thesis of Guidance and Counseling, Tehran: Alzahra University.

AkbariCharmahini, S. (1999). Comparative Study of Adaptive Behavior of Gifted and Normal Students Studying in the Elementary School in Isfahan. MA Thesis, General Psychology, Tehran: Tarbiat Modarres University.

AlamMehrjerdi, Z. (2003). The Relationship between Religious Attitudes, Altruism and Social Adjustment in Students of Zahra University. MA Thesis, General Psychology, Tehran: University of Alzahra.

Averill, J. (2013). Individual Differences in Emotional Creativity: Structure and Correlates. Journal of Personality, 67, 331371.

Behpazhouh, A, Kehtari, F., \& Ejei, J. (2008). Comparison of Mental Health and Social Adjustment of Gifted Female Students in Three Educational Settings. Journal of Psychological Science, 7, 494-511.

Darkeh, M., Askari, S. Mohammadi, J., \& Rezaei, H. (2011). Comparing EI and Social Adjustment of Gifted Students and Normal Students of Kermanshah. Iran's First National Congress of Social Psychology, 79.

Ebrahimi, E. (2006). Comparing and Investigating the Relationship of Styles of Coping with Mental Stress, Emotional Creativity and Mental Health of Athlete and Non-Athlete University Students. MA Thesis, General Psychology, Tehran: Tehran Teacher Training University.

Eisazadegan, A., Michael Monie, F., Jenaabadi, H., \& Gholinejad, F. (2013). Comparing Thinking Styles and Emotional Creativity among Gifted and Normal Students. Journal of Exceptional Individuals’ Psychology, 3, 87-105.

Ghadirinejad, F. (2002). Preliminary Standardization of Emotional Creativity Scale (ECI) on Students of Tehran University. MA Thesis, Psychology, Tehran: Tehran Teacher Training University, 38-55.

HosseinKhanzadeh, A. A. (2013). Psychology and Education of Children with Special Needs. Tehran: Publication of Sound of Light.

Kim, J., \& Michael, W. B. (2011). The Relationship of Creativity Measures to School Achievement and to Preferred Learning and Thinking Style in a Sample of Korean High School Students. Educational and Psychological Measurement, 55, 60-74.

Kershner, J. R., \& Ledger, G. (2007). Effect of Sex, Intelligence, and Style of Thinking on Creativity: A Comparison of Gifted and Average IQ Children. Journal of Personality and Social Psychology, 48, 133-140.

Kousari, E. (2001). Comparing the Effect of Gender and Control Source on Personal and Social Adjustment of High School Students. MA Thesis, Educational Psychology, Shiraz: Shiraz University.

Lehman, E. B., \& Erdwins, C. J. (2014). The Social and Emotional Adjustment of Young, Intellectually-Gifted Children. Gifted Child Quarterly, 25, 134-137. http://dx.doi.org/10.1177/001698628102500311

Pasha Sharifi, H., \& Ghodrati, M. (2010). Examining Creative Talent of Gifted Female Students Studying in Schools for Exceptional Talents, Private and Public Schools. New Journal of Industrial/Organizational Psychology, 1, 31-40.

Pourakbaran, E. (2013). Study and Comparison of Social Adjustment and Self-Esteem in Blind \& Normal Students of TorbatHeydarie. Journal of European Psychiatry, 28, 1-18.

Razavian Shad, M. (2005). The Relationship of Emotional Intelligence with Social Adjustment and Academic Achievement of Third Grade Middle School Students in Tabriz. MA Thesis, Educational Psychology, Tabriz: University of Tabriz.

Sabri, M., Alborzi, M., \& Bahrami, M. (2013). Relationship between Family Communication Patterns, Creativity, Emotional Intelligence in High School Students. Journal of Modern Psychology, 9, 35-63.

Stoltzfus, G., Nibbelink, B. L., Vredenburg, D. and Hyrum, E. (2011). Gender, Gender Role, and Creativity. Social Behavior and Personality: An International Journal, 39, 425-432. http://dx.doi.org/10.2224/sbp.2011.39.3.425

Suragy, C. (1996). Comparison of the Characteristics of Creative and Non-Creative Students in Schools for Exceptional Talents in Birjand. MA Thesis, Counseling Psychology, Tehran: Allameh Tabataba'i University.

Yarmohammadian, A., \& Sharafirad, H. (2011). Analysis of the Relationship between Emotional Intelligence and Social Adjustment in Adolescents. Journal of Applied Sociology, 22, 35-50. 